\title{
EL DR. HANS VON DER GABELENTZ \\ Y LAS PINTURAS DE LA ACADEMIA DE SAN CARLOS
}

XAVIER MOYSSÉN

Con el propósito de reunir para su publicación, todo cuanto de interés crítico y documental se ha escrito sobre las pinturas existentes en las viejas galerias, de lo que fue la Academia de San Carlos y dada la poca importancia que se ha otorgado al estudio de tales obras, dediqué mis empeños, hace algunos años, a recabar un material importante que se encuentra inserto en folletos y revistas de difícil acceso hoy en día, cual es el caso, por ejemplo, del trabajo de Manuel Francisco Alvarez, "Las pinturas de la Academia Nacional de Bellas Artes, su mérito artístico y su valor comercial". ${ }^{1}$ La tarea, he de confesarlo aquí, no pasó más allá de los buenos propósitos, quedó sin conclusión.

Uno de los principales obstáculos que se presentan para el estudio de los cuadros europeos, es la carencia de noticias referentes a la procedencia de los mismos. En las galerías, desde su fundación, no se llevó ningún registro o archivo sobre el origen de las obras, ni mucho menos de aquellas que se adquirieron a partir de la segunda mitad del siglo xix. Inútil es el pretender encontrar certificación alguna de esa época, y menos aún juicios criticos respecto a las adjudicaciones que se hicieron a tal o cual maestro o escuela, más con buenos deseos que con autorizados conocimientos en la materia. Ciertos ouadros provienen de colecciones particulares, las cuales se formaron mediante adquisiciones bien en el extranjero, o bien con obras existentes en el país desde la época del virreinato. Salvo un caso excepcional, el de la colección de Eustaquio Barrón, no hay catálogo impreso sobre los cuadros reunidos en las colecciones decimonónicas. Al parecer esa documentación si la hubo, se perdió para siempre, a menos que algún día aparezca en los viejos archivos notariales.

En rigor no se ouenta con nada confiable, hasta donde mis noticias llegan, respecto a las colecciones formadas en Europa después de la Primera Guerra Mundial y cuyos cuadros pasaron a enriquecer las galerías de la Academia. Me refiero, de manera particular, a las dos que pertenecieron a Alberto J. Pani. ¿Dónde quedó la documentación de esas pinturas? Es decir, la historia de las mismas, su procedencia. ¿Quiénes

1 Fue publicado en las Memorias de la Asociación de Ingenieros y Arquitectos de México. México, 1914, pp. 249-316. 
fueron sus poseedores anteriores; las casas de los marchands en que se adquirieron, así como las cantidades erogadas? ¿A quiénes y desde cuándo, se deben las adjudicaciones con las que aparecen clasificadas? Son preguntas que no encuentran respuesta satisfactoria, a pesar del catálogo que preparara el doctor Atl, cuyo mérito mayor estriba en la reproducción de las pinturas y dibujos reunidos por Pani, que no así en sus arriesgados y divertidos comentarios. ${ }^{2}$

Se han ocupado de las pinturas europeas de las galerías de San Carlos, con un criterio más bien historicista que no estético, recogiendo noticias de distinta procedencia, entre otros el ya citado Manuel Francisco Álva. rez, quien además de ofrecer datos valiosos sobre la historia de la Academia y sus pinturas, también entrega noticias sobre otras obras procedentes del viejo continente y que él vio en poder de distintas personas; se ocupa, asimismo, de la salida del país de diversos cuadros debidos, según él, a afamados maestros de la pintura europea, Su estudio es de indudable valía por las relaciones que incluyó sobre los cuadros que formaban las tres colecciones más importantes que se reunieron en México, durante el siglo XIx. Aunque el suyo es más bien el trabajo de un amateur, no obstante, resulta imprescindible pues muchos cuadros de esas colecciones pasaron a las galerías.

El primer trabajo sistemático sobre las pinturas de maestros europeos, reunidas en las galerías de la Academia, se debe a Luis Cardoza y Aragón y a Xavier Villaurrutia. Con todos los peros y errores que se les puedan objetar, de lo que ellos, por lo demás, fueron conscientes, su catálogo es hoy en día una fuente confiable en las noticias que consigna, sobre todo en la procedencia de ciertas obras. Una novedad que introdujeron fue la división de las pinturas por escuelas, con todo y los riesgos que ello supuso. Sobre cada artista se ofrece una mínima y útil nota biográfica. Partiendo del alcance de sus conocimientos en la materia, optaron por el siguiente criterio:

Juzgamos poco oportuno hacer consideraciones críticas en el catálogo. La inmensa complejidad permanente del problema nos habría llevado a consideraciones discutibles... algo semejante habría acontecido con la aceptación de más escuelas, con la filiación a ellas, con la determinación de artistas que las han formado o se han formado en ellas. Aun de manera superficial, sin abordar los diversos aspectos

${ }^{2}$ Catálogo de las pinturas y dibujos de la Colección Pani. Texto del Dr. Atl México "Universidad Nacional. 1921. 
que ofrece el estudio de las influencias, habría sido aventurado guiarnos por este o aquel autor, contradicho ya, discutible siempre, no aceptado plenamente por nosotros mismos, para terminar afirmando o negando algo que seguiríase dudando, como en el caso de tal problema estético de resolución siempre provisoria por tratarse de problemas permanentes. Consideramos más razonable no dejar sino afirmaciones clásicas, tradicionalmente aceptadas y fundadas, verdades casi indiscutibles que de época en época se revalorizan por la crítica con nuevos aspectos parciales y sentidos generales. ${ }^{3}$

A Manuel Toussaint se debe también, una apreciación histórica sobre algunas obras de las galerías, a más de otras pertenecientes a colecciones particulares. Un equilibrado criterio artístico le impidió caer en comprometidas adjudicaciones. Las noticias que reunió referentes a los coleccionistas del siglo xIx, nos muestran un aspecto importante y poco conocido del arte pictórico en México ${ }^{4}$ Respecto a los cuadros de escuela española, Diego Angulo Íñiguez se encargó de su estudio, mismo que no ha perdido su validez, en consiguiente ninguna novedad se encuentra después de la fecha de su publicación. Angulo Íñiguez también hizo valiosas aportaciones críticas respecto a otras obras, no españolas, existentes en las galerías. ${ }^{5}$

Sé de la existencia de un "Indicador" de cuadros de la Academia, debido al pintor y restaurador Juan M. Pacheco, entiendo que se trata de una obra mediocre y nada más. Por su parte Abelardo Carrillo y Gariel se ocupó tanto de la formación de las galerías, como de los cuadros europeos Estimo de un valor superior la primera obra, por las noticias históricas en ella contenidas. ${ }^{6}$ No sucede lo mismo con la segunda, que incluye además, noticias sabre pinturas virreinales y dei siglo XIX. En el breve espacio en que se ocupa de los cuadros europeos, no hizo otra cosa que repetir las informaciones tradicionales sobre la procedencia de algunas obras y sus falsas adjudicaciones; no hay aportación significativa. ${ }^{7}$ Como menos aún, podía hacerla Fernando Leal, en el brevísimo y desorientador prólogo que acompaña a su catálogo del Museo

3 Vid. Museo Nacional de Artes Plásticas, Catálogo de Pinturas. Serción eturopea, México. Ediciones del Palacio de Bellas Artes. 1934, p. 13.

4 Obras maestras de la Pintura Europea en México. Texto de Manuel Toussaint. Sociedad de Arte Moderno. México, 1946.

5 Vid, "La Academia de Bellas Artes de México y sus pinturas españolas", en Arte en América y Filipinas. I. Sevilla, 1935.

6 Las galerias de pintura de la Academia de San Carlos. UNAM. México, 1944.

7 Las galerias de San Carlos, México. Enciclopedia Mexicana de Arte. 6, México, 1950. 
de San Carlos; para no quedarse atrás echó también su cuarto de espadas en las atribuciones. ${ }^{8}$

Los estudios dedicados a las pinturas europeas de las galerías de San Carlos, por parte de críticos e historiadores extranjeros, no son numerosos; salvo el caso de las obras españolas que merecieron la autorizada atención de Diego Angulo íniguez, las correspondientes a otras escuelas han corrido con menor fortuna. En los años intermedios de la segunda década de este siglo, se ocupó tanto de los cuadros europeos como de los coloniales, el alemán Hans von der Gabelentz, sus comentarios, tema central de este trabajo, se publican a continuación. Hacia 1946 el crítico italiano Lionello Venturi estuvo en México. En poder de Francisco de la Maza vi unos apuntes manuscritos que tomó, sobre los comentarios que Venturi hizo ante las pinturas de la Academia. Recuerdo vagamente algunas de las opiniones del célebre crítico, del que no sé si llegó o no, a publicar trabajo alguno respecto a sus observaciones; de allí que hoy lamente profundamente el no saber qué destino tuvieron los citados apuntes hechos por De la Maza.

Soy de la opinión que los cuadros de la Academia, procedentes de distintas escuelas europeas, sólo han merecido un detenido y autorizado análisis crítico y ése es el que efectuó en 1969 Jaromir Neumann, prestigiado conocedor checoeslovaco. Comparto el principio establecido de que cada pintor requiere de la atención de un especialista, bien sobre él o sobre la escuela a la que pertenece; no obstante, me parece que los conocimientos de Neumann respecto a la pintura europea, son sólidos, a más de respaldarle siempre una acuciosa investigación histórica al respecto. Fuera de las telas españolas, nadie antes de él, ha visto y estudiado con cuidadoso esmero, pintura tras pintura, como lo indica el informe que rindió. Jaromir Neumann vina a México enviado por la UNESCO y a solicitud de José Luis Martínez, quien representaba al Gobierno Mexicano a través del Instituto Nacional de Bellas Artes. Lástima es que sus investigaciones no hayan ido más allá del informe oficial que se vio obligado a rendir y en consecuencia, que no conozcamos sus conclusiones definitivas sobre los cuadros de las antiguas galerías de la Academia. ${ }^{9}$

8 Publicado por el Instituto Nacional de Bellas Artes. México, 1958.

9 Tengo a la vista y de ella me he valido, una copia del reporte que Neumann entregó, al concluir la primera etapa de sus estudios; lleva el siguiente título: Colección de obras pictóricas de Europa Occidental del Museo de San Carlos de la Ciudad de México. 
No he logrado precisar el año en el que Hans von der Gabelentz estuvo en México, pero a juzgar por las fechas de publicación de sus estudios de las pinturas de la vieja Academia, él debió verlas hacia 1925. El primer trabajo dedicado íntegramente a los cuadros europeos, apareció en Berlín hacia 1926, el segundo, que dedicó a la pintura de la Nueva España, vio la luz un año más tarde. ${ }^{10}$ En realidad nada sé en concreto sobre el doctor Gabelentz; por el carácter de sus escritos parece ser que se trataba, más bien, de un excelente amateur que no así de una autoridad en un campo tan vasto como son las escuelas europeas de pintura. Jaromir Neumann escribió al respecto las siguientes líneas:

Es una de las primeras tentativas para abordar las obras de valor de la colección de una manera crítica y bajo el aspecto de la historia del arte. Aun cuando el autor usa el método comparativo moderno, su estudio tiene un sorprendente número de conclusiones erróneas. Las características de algunas obras, muy someras, carecen de observación exacta y con frecuencia, también de juicio crítico. ${ }^{11}$

Sea cual sea el valor de sus opiniones en la época en que las escribió éstas debieron constituir una novedad en el medio cultural mexicano, mas no fue así, nunca se le citó y cuando se hizo fue por la resonancia de ecos lejanos, pues se llegó a hablar de "su libro", que por supuesto nadie conocía, más por ignorancia del idioma que por la inexistencia del mismo. No voy hacer mayor comentario a lo que escribió Gabelentz sobre los cuadros europeos, creo que es suficiente con lo que anotó autorizadamente Jaromir Neumann; en todo caso lo dicho por el doctor alemán, resulta hoy un texto histórico de un valor relativo. Me parece, en cambio, que lo que observó de la pintura colonial no es del todo desechable.

Hans von der Gabelentz conoció la pintura virreinal a través de los cuadros exhibidos en las galerías, más aquellos que vio durante las visitas que hizo a iglesias y catedrales, entre estas últimas las de México, Puebla y Guadalajara. Las únicas fuentes impresas con las que se auxilió,

10 "Die Akademie San Carlos in Mexico", en Repertorium Fur Kunstwissenschaft. Band 47, pp. 144-154. Band 48, pp 129-130. Berlín Leipzig, 1926-1927. Debo a la generosidad de la doctora Helga Kropfinger-von Kügelsen, de la Universidad de Berlín, RFA, las copias de los estudios del Dr. Gabelentz; de la traducción al español se encargó la señora Sandra Montaño de Foncerrada. Para ellas queda aquí el testimonio de mi agradecimiento.

11 En su reporte a la UNESCO y al Instituto Nacional de Bellas Artes 
al parecer, fueron el libro de Francisco Pérez Salazar sobre la pintura en Puebla, y el pésimo folleto de Agustín Fernández Villa, pues los cita en sus obras; es más, sospecho que a Pérez Salazar debió conocerlo personalmente en la Puebla de los Ángeles. Nada aprovechó de lo publicado por Manuel G. Revilla y Manuel Romero de Terreros.

Su estudio lo inició con el tema obligado para los extranjeros no españoles, o sea, el control totalizador de la Iglesia católica sobre las conciencias, en este caso a través del arte pictórico; de allí la importancia que tuvo según sus observaciones, el culto mariano y la extensa iconografía que propició. Con buen juicio anotó que la pintura colonial era no sólo hija de la pintura española, lo era también de la italiana y desde luego era tributaria también, de la flamenca, con Rubens a la cabeza. Sin embargo, con un criterio mayor supo ver que "aunque el arte mexicano es un arte derivado, no se le puede negar su originalidad provinciana y se le reconocerá de buena gana a algunos de sus representantes, el haber logrado crear con sus propias fuerzas . utilizando obras de arte extranjeras como inspiración".

Valiosos comentarios hizo sobre los maestros que llamaron su atención, tales como Baltasar de Echave, el viejo, Luis Juárez y Sebastián de Arteaga. Se interesó asimismo por los pintores barrocos del dieciocho, en especial por Miguel Cabrera y José de Ibarra, de quien le molestó le emparentaran con el estilo de Bartolomé Esteban Murillo, pues él encontró que con quien mejor se relacionaba, era con el italiano Carlo Maratta, en consecuencia había que llamarlo jel Maratta mexicano!, ni más, ni menos.

A continuación se insertan los dos textos del doctor Gabelentz, como una contribución a la historiografía de la pintura en México, en este año en que se celebra el segundo centenario de la fundación de la Academia de San Carlos.

Una observación final, el lector advertirá que la catalogación que da el autor sobre las obras que estudia, hace mucho que ha dejado de existir, no obstante mantuve el criterio de respetar la que Gabelentz encontró durante sus visitas a las desaparecidas galerías del edificio de la Academia.

C. U., noviembre 16 de 1981 
Dr. HANS VON DER Gabelentz

\section{LA ACADEMIA DE SAN CARLOS EN MÉXICO}

Situada lejos de las calles principales por las que suelen caminar los eruditos alemanes en arte, la colección de pinturas de la ciudad de México, la Academia de las Nobles Artes de San Carlos de la Nueva España, ha recibido hasta ahora poca atención. Las siguientes notas deberán informar de manera concisa sobre algunas de sus obras principales, las cuales, mientras no exista ningún catálogo científico permanecerán medio olvidadas y en mayor o menor grado excluidas del estudio artístico.

Fundada por el rey Carlos III de España en 1778, la colección se enriqueció, después de las así llamadas Leyes de Reforma, con algunas posesiones antiguas de la Iglesia. Contiene unos cientos de cuadros del arte colonial mexicano, de la pintura europea antigua y más moderna, que se encuentran distribuidos en ocho salas más o menos grandes. Los originales y las copias no están separados, de manera que sólo las dos primeras salas en las cuales han sido reunidos los cuadros de la escuela mexicana, dan una impresión de unidad. Nosatros nos dedicaremos por lo pronto a la pintura europea.

\section{Escuelas extranjeras. Holandeses de los siglos XV y XVI}

№ 326 (Escuela de Nürenber del siglo xv). 1 Resurrección de Lázaro. Lázaro envuelto en paños blancos está sentado en el centro de la parte anterior del cuadro sobre la tapa del sarcófago abierto. Eleva implorante sus manos hacia Cristo, el cual se voltea hacia él, en ademán de hablarle. Uno de los discípulos (Pedro) sostiene en la mano derecha una cuerda con la cual estaba amarrada la mortaja. A la izquierda adelante está parada Marta ataviada con un rico vestido de la época de color verde olivo, atrás de ella aparecen cuatro de los discípulos. En el lado derecho del cuadro frente a este grupo se encuentra Maria arrodillada; la reconocemos por su largo pelo rubio que cae en rizos sobre los hombros, atrás están parados cinco judios. Tres de ellos se distinguen por sus sombreros fantásticos y llenos de colorido, el hombre situado hasta adelante de barba oscura y vestido con un abrigo de brocado rojo se tapa la nariz. El centro del cuadro está formado por una calle guamecida por altas casas romanas rematadas por torres y lo separa de la parte anterior una pared baja que tiene enmedio una puerta enrejada con tres escalones. Dos pequeñas figuras masculinas tambión con unas gorras altas y fantásticas, están a punto de pasar por la puerta semiabierta. Entre las casas pintadas de vivos colores que enmarcan el centro del cuadro, como los bastidores de un escenario, por encima de una pared baja y almenada se observa el amplio panorama de un lago lleno

1 Los nombres y las indicaciones que aparecen entre paréntesis corresponden a aquellas que llevan los cuadros en el museo. Algunas fotografías que aquí son reproducidas se las debo a la amabilidad del director del Museo, Sr. Ramos Martinez, de México. 
de cisnes, de grupos de árboles oscuros, de una ciudad llena de torres y un río que serpentea por un paisaje montañoso y que desaparece en el horizonte. El cuadro se distingue por colores brillantes y bien balanceados en todas las superficies, y una técnica de miniatura hasta en todas las partes del fondo. En los tipos masculinos sobresalen determinadas caras ovaladas y con frentes despejadas, "bolsas debajo de los ojos" y labios inferiores muy prominentes No cabe la menor duda que el cuadro es de un holandés de la mitad del siglo xv. La construcción y el tratamiento de los planos centrales y posteriores tienen un parecido notable con el paisaje del cuadro de Frankfurt: "La Sibila Tiburtina le profetiza al Emperador Augusto el nacimiento de Cristo" que anteriormente llevaba el nombre de Dirk Bout. ${ }^{2}$

La figura de Cristo y el discípulo que está detrás de Él, que tiene las manos juntas y una expresión interrogante en los ojos, son casi iguales a las figuras correspondientes de La Resurrección de Lázaro, en Berlín, de Albert van Ouwater, que también representa un cierto parecido en la contraposición de los dos grupos principales. Las manos de dedos cortos según Wurzbach, ${ }^{3}$ características de Ouwater también aparecen en nuestro cuadro, el que atribuímos a un artista holandés (de Harlem) del círculo de Dirk Bout o de Albert van Ouwater. Debe haber sido pintado entre 1450 y 1460 .

No 328 (Maestro desconocido de la Escuela Flamenca del siglo xv). La Virgen y el niño. Busto de María con el Niño situado delante de una galería abierta, que está separada del margen del cuadro al frente por un pretil que permite la vista a un paisaje lleno de árboles y un molino de agua.

La cabeza de María, que está cubierta por la túnica que envuelve su figura, se inclina un poco hacia el Niño que se mueve con viveza sobre la mano izquierda de su madre, con la mano derecha agarra una esquina de paño blanco sobre el cual está sentado, y con la izquierda juega con una cadenita de coral rojo. Todos los elementos ornamentales de la arquitectura son de un depurado estilo renacentista. Los prototipos de estos agradables grupos los podemos distinguir desde la "Virgen con Santos y Fundadores de la Orden" de Memling (Klass, d, Kunst $2 / 3$ y 4, después ca 1468). El altar de San Juan, en Brujas del mismo maestro (Klass. d. Kunst. 31 del año 1479) sus Vírgenes en Viena (Klass. d. Kunst 117) y Florencia (Klass. d. Kunst 116). Sobre todo los dos últimos cuadros nos recuerdan al de la Academia por su galería renacentista que se abre hacia atrás y que tiene vista sobre un paisaje. La posición de las manos de la Virgen se podría comparar con la de las Vírgenes en los siguientes cuadros: María en la "Adoración de los Reyes" en Munich (35) y la Virgen en el Louvre (Klass d. Kunst 65). Sólo que los tipos de Memling son más tímidos, más góticos, la caída de los pliegues se quiebra en ángulos más agudos, los elementos ornamentales son todavía vacilantes en su moderno desarrollo. (Los ornamentos de los soportes de los arcos de medio punto en las pinturas de Viena y Florencia

2 a.a. O. II, 292,

3 Wurzbach, Niederländisches Künstlerlexikon I, 64 "I otalmente desconocido, posiblemente otro maestro". 
dan una clara impresión del estilo gótico tardio, mientras que la ornamentación, dividida en motivos individuales, de la viguería horizontal del cuadro de la Academia, lleva el sello manifiesto del estilo renacentista.) El nombre de Memling nos señala el camino a Brujas. Gerard David, cuyo tratamiento más suave de las formas invita a la comparación, siempre representa al Niño Jesús vestido.

Nuestro cuadro puede atribuirsele a un hábil y cuidadoso seguidor de Memling de la época entre 1500 y 1510 .

No 326 (Escuela Flamenca desconocida alrededor de 1500) La Sagrada Familia. María, vestida con abrigo azul obscuro y un vestido gris que en la sombra se ve violeta está sentada (a la izquierda del cuadro) en un trono gótico con el Niño Jesús en su regazo al que Santa Ana le ofrece una manzana. Santa Ana lleva una pañoleta blanca en la cabeza, un abrigo café oscuro forrado de verde sobre un traje rojo, su mano derecha se apoya sobre un libro. Detrás de los brazos del ancho trono semejante a una banca, aparecen a la izquierda: San Joaquín, con turbante y traje rojo, a la derecha, Santa Isabel, también ataviada con un turbante y debajo de éste un paño blanco. Su vestido es rosado y violeta, su abrigo azul. Sus manos están cruzadas sobre el pecho. Sobre el respaldo del trono vuela la paloma del Espíritu Santo con su aureola. El tema y el tratamiento del color señalan hacia Amberes-Bruselas. Quinten Massys estableció con su famosa pintura de La Sagrada Familia, de 1509 (Museo de Bruselas) un modelo que siguió teniendo consecuencias hasta La Sagrada Familia de Jan van Coninxloos (jsobre 1540 - 46?) también en el Museo de Bruselas. Nuestro cuadro es más afín al maestro más viejo y debe haber sido creado entre 1510-20.

No 340 (Pintor flamenco desconocido del siglo xv), Cristo en la Crü, la cabeza inclinada hacia la izquierda, cubierto con unas enagüillas que ondean en el viento. Maria, que aparece a la izquierda, arrodillada sin fuerzas en el suelo tiene una espada en el corazón. Sus manos descansan lacias en el regazo, su cabeza está hacia abajo, una pañoleta blanca y un abrigo azul cubren a la figura. Atrás de Ella está San Juan, todo vestido de rojo. Su mano derecha se posa en el hombro de María mientras que la izquierda descansa sobre su pecho. Al otro lado de la Cruz está María Magdalena con la cabeza ligeramente inclinada hacia la izquierda, las manos levantadas delante del pecho (con las palmas hacia fuera) "Está vestida con un rico traje según la moda, un vestido verde con mangas rojas, túnica azul forrada de gris y una pañoleta blanca. Al frente a la derecha están el cráneo y los huesos de Adán. La parte anterior está pintada de verde olivo hasta azul verde, la posterior, más de verde claro. En esta última se distinguen las murallas de Jerusalén, las montañas y el mar. Es evidente que el cuadrito que se distingue por su brillante armonía multicolor fue pintado en el sur de los Países Bajos (Amberes) a principios del siglo xvi $y$ no es ajeno al taller de Quinten Massys.

Nọ 374 (Pintor Napolitano desconocido del siglo xv). Media figura de la Virgen de tamaño natural que abraza al Niño Jesús que está de pie 
en su regazo. Un fino velo transparente rodea el cuerpo desnudo del Niño. El abrigo rojo de María cubre casi totalmente su figura y de su vestido azul se ve poco. La Madre y el Niño tienen el pelo rubio (los nimbos de rayos: fueron agregados después), el fondo es negro. En este grupo de la Virgen se hace evidente un sentido italiano de la forma, el cual sin embargo está todavía poco desarrollado y de ninguna manera ha trascendido al estilo holandés. El pintor pertenece a la Escuela de Amberes, donde Quinten Massys o el maestro de la Muerte de María revelan, como èl, un romanismo timido parecido. Según la época el cuadro podría haber sido pintado en el primer cuarto del siglo xvi.

No 344 (Pintor desconocido del siglo xv). Cristo en el Limbo. El centro del cuadro está ocupado por unas ruinas donde aparece Cristo. Lleva en la mano derecha una bandera de los cruzados, con la otra mano toma a Adán por la muñeca. Junto, es decir, detrás de éste aparecen Eva y los demás habitantes del Limbo dentro de una arquitectura de arcos de medio punto que tiene una escalera que lleva hacia adelante. A la derecha, en la parte del fondo del cuadro, hay un paisaje montañoso fantástico con pequeñísimas figuxas que son sometidas a diferentes martirios del infierno. Un cielo nocturno con destellos rojos y amarillos se extiende sobre todo esto. A la izquierda vemos condenados que sufren toda clase de castigos sobre una colina parduzca bajo un cielo azul negro. Lo figurativo y la iluminación, que producen una impresión igualmente fantástica, recuerdan totalmente a Gerónimo Bosch, el no superado descriptor de figuras fantasmagóricas del infierno. Compárense las escenas infernales en las pinturas de la Bajada a los Infiernos, la Tentación de San Antonio, del Juicio Final, que se conservan en varias repeticiones. Felipe II donó el 15 de abril de 1574 al Escorial, varias pinturas de Gerónimo Bosch, entre ellas una Bajada de Cristo a los Infiernos, 4 ahora perdida. Tal vez en nuestro cuadro no estemos frente a una pintura original pero sí ante una reproducción de taller del cuadro perdido.

No 352 (Sin título). Pequeño tríptico. En el centro aparece Cristo en una nube de ángeles acompañado por liberados del Limbo, su Madre a la derecha al frente arrodillada en un reclinatorio La hoja izquierda: Cristo en la Co. lumna. La hoja derecha: Cristo en la Cruz Holandés no determinado del primer tercio del siglo $\mathrm{xvI}_{\text {. }}$

Nọ 338 (Tríptico flamenco), Creación de Eva. Adán duerme en el suelo. Por la izquierda se acerca Dios Padre semisuspendido en el aire, los ángeles le sostienen la túnica sobre la cabeza, la que, circundada por pelo gris ondulado, lleva una corona. La mano derecha está levantada en el gesto de hablar, con la izquierda toma a Eva por la muñeca. Eva, cuyo perfil ve hacia la izquierda eleva ambas manos hacia Dios Padre. Un cielo nublado y oscuro forma la parte del fondo, ahí aparece muy pequeña la Caída de los Ángeles. Los ángeles caidos son convertidos en toda clase de sabandijas, el infierno parece una ciudad ardiendo.

4 Wurzbach a.a, O.I., 141 
El Pecado Original. Adán, en posición de caminar a la izquierda se voltea de perfil hacia Eva, cuya mano derecha está colocada sobre el hombro de Adán, con la izquierda toma la manzana que la serpiente le ofrece del árbol. El fondo lo ocupa un árbol oscuro con sus ramas y sus hojas, a la izquierda adelante está acostada una gata gris vista totalmente de frente. Expulsión del Paraiso. Adán cae hincado con un violentísimo movimiento hacia la derecha, el brazo derecho está extendido, el izquierdo se lo lleva a su cabeza levantada. Eva camina junto a él con grandes pasos, tiene ambas manos sobre la cabeza como protegiéndose, mientras que el arcángel Miguel blande su espada sobre los expulsados. También aquí el fondo lo ocupa un árbol de hojas oscuras. Los tres cuadros pertenecen a un altar de tres hojas cuyo estilo señala a Baldung Grien y Durero. Alto Alemán alrededor de 1520.

\section{Pintores españoles de los siglos XVI hasta XVIII}

No 332 Luis de Morales (1509-1586). Piedad. Busto en tamaño natural de María con el cadáver de Cristo. María, caracterizada por una barbilla larga y puntiaguda, nariz larga y párpados con sombras oscuras, asi como por dedos delgados y puntiagudos, forma con sus vestiduras oscuras un contraste muy efectivo con el color parduzco cadavérico del Hijo muerto, a cuya cabeza Ella estrecha amorosamente su mejilla. La interpretación del Muerto con la boca abierta y un ojo medio deforme es terriblemente naturalista pero muy característico del pintor español que tenía una predilección por los temas sombríos. Comparar con La Piedad de la Academia de San Fernando en Madrid. 5

Jusepe Ribera (1588-1656). La colección contiene tres obras de este pintor.

No 266 Labán con sus rebaños, 6 totalmente definido hacia un efecto de claroscuro, en la parte sombreada oscurecido hasta negro opaco Los animales representados demuestran una buena observación de la naturaleza. Esta obra personal forma probablemente un contraste con el "Sueño de Jacobo" de Rivera de 1633 (Madrid, Prado), "Jacobo con el rebaño de Labán" de 1634 (Escorial). "La bendición de Jacobo" de 1637 (Madrid, Prado). La otra pintura No 244 representa a Gristo, al cual, antes de ser clavado en la cruz, le son robadas sus vestiduras.

No 248 Francisco de Zurbarán (1598-1662). Cristo en Emaús. Cristo, con un sombrero de ala ancha que sombrea su cara y sólo le deja la parte derecha iluminada, está en el momento de partir el pan. A la izquierda está sentado Pedro. Un rayo de luz cae sobre su espalda, su manga derecha y la nuca, el rostro permanece en las sombras. Frente a $\mathrm{k}$, Cleofas contempla al Señor lleno de emoción. A los pies de Pedro está sentado un perrito. El cuadro fue alguna vez propiedad de la ahora profanada iglesia agustina de México y es de la época más madura del artista. 7 Colores calientes y amortiguados, una ilumina-

5 Reproducción de A. L. Mayer (Historia de la Pintura Española I, 217 No 123) Gesch. der Span Materei.

${ }^{6} \mathrm{Z}^{\mathrm{O}} \mathrm{O}$ el sueño de Jacobo? I Moeses XXXI, II ff.

7. No mencionado por H. Kehrer, Francisco de Zurbarán. 
ción llena de efecto, profundidad espiritual y la hábil agrupación de las figuras le confieren al cuadro el rango de una gran obra maestra.

Nọ 235 (Maestro desconocido). San Agustin. Figura de tamaño natural orientada hacia la derecha. El Santo, vistiendo un hábito oscuro sostiene en las manos un libro grande abierto en el cual se concentra "Su cabeza adornada con la mitra está inclinada ligeramente. La figura oscura se destaca con nitidez del fondo claro, sólo la parte posterior de la mitra, la nuca, una parte de la mano derecha y del libro están iluminadas. El efecto de la pintura radica totalmente en el contraste de la figura poderosa y oscura del santo, que ocupa casi toda la superficie del cuadro, con el fondo azul-gris claro, donde se puede ver el encuentro del santo con el muchacho a la orilla del mar.

No 288 (Maestro desconocido). San Juan de Dios con hábito de fraile sosteniendo una cruz en la mano derecha, dirige su mirada extasiada hacia el cielo. Un paisaje rocoso más oscuro y el cielo claro forman el fondo del cuadro sobre el cual se dibuja con claridad la figura del Monje (iUna aparición típicamente española!).

Los dos cuadros forman un conjunto y son sin duda alguna trabajos personales de Zurbarán, y tienen una gran correspondencia con sus cuadros de grandes figuras de santos en Cádiz, Sevilla con sus u a. a. o. Comparar especialmente con el San Hugo, en el museo de Cádiz. ${ }^{8}$

Nọ 270 Juan Carreño de Miranda (1614-1685). Retrato de Doña Mariana de Austria, viuda de Felipe IV. Aparece vestida con traje de abadesa y sentada en una silla de brazos ante un escritorio. El cuadro es una reproducción de los cuadros en Munich y en el Museo del Prado, pero es menos expresivo que éstos y probablemente sólo un trabajo de taller.

A Bartolomé Esteban Murillo (1617-1682) se le atribuyen en la Academia varios cuadros como trabajos personales: No 274, San Juan Bautista como niño, bebiendo agua de una fuente, junto a él está sentado un cordero. La cabeza, el hombro y el brazo izquierdo del muchacho están iluminados con claridad, todas las partes de sombra están oscurecidas.

No 268 San Sebastián, acostado a la derecha en el suelo, sus manos están amarradas sobre su cabeza. Por la izquierda se acercan Santa Irene y una sirviente, un ángel aparece arriba. Nọ 272: San Juan de Dios. Los tres cuadros están muy oscurecidos y se encuentran en un estado que no admite un juicio concluyente. La mejor obra salida de las manos de Murillo parece haber sido la de la Inmaculada Concepción de la Catedral de Guadalajara; la cual sin embargo se encuentra perdida. 9 De los numerosos cuadros de ia Inmaculada Concepción, el del Prado es el más parecido al nuestro, pero éste tiene en el fondo una nube con angelotes con toda clase de símbolos y alegorias, que falta en el cuadro de Madrid y también en los otros.

8 H. Kehrer A A.O. Reproducción 32

9 Durante mi visita a Guadalajara ya no la vi y es posible que haya sido sacada del país durante la última revolución de 1924 (¿ a los E.E. U.U.?) Napoleón III trató inútilmente, durante la aventura mexicana de 1867, de quedarse con el cuadro. 
De dos naturalezas muertas № 256 y № 257, que sin motivo se atribuyen a Nateo Cerezo (1635-1685), en la segunda, con una representación de pescados, recipientes de cobre y de barro y una vasija de latón tiene un encanto lleno de color.

José del Castillo (1737 hasta 1790) : Busto en tamaño natural de San Francisco de Asís en un marco ovalado. El Santo vestido con un hábito café, sostiene un crucifijo delante del pecho. Ante él están puestos unos cráneos y un libro. El fondo de nubes de un sombrío color azul realza con claridad la figura del Santo que dirige su mirada extasiada hacia el cielo

\section{ITALIANOS}

No 333 (sin título). Busto de la Virgen con el Niño de pie ante un cortinaje verde. A la izquierda una ventana abierta a través de la cual se tiene una vista de una ciudad llena de torres. Taller de Cima de Conegliano (echado a perder).

No 237 (iLeonardo da Vinci!) Bustos de las tres virtudes teologales y de las cuatro virtudes capitales. Las cabezas de las cuatro mujeres están estrechamente apretadas unas contra otras. La Prudencia, la Justicia, la Fortaleza y la Templanza llevan diademas en el pelo con los símbolos a ellas correspondientes. De las virtudes teologales la Caridad aparece con un abrigo de color rojo cobrizo acompañada de un niño, uno de los cuales, que tiene la cabeza vivamente echada hacia atrás, es casi un recuerdo de Miguel Ángel. La piel parduzca de todas las figuras tiene un color cadavérico desagradable $\mathrm{El}$ creador de este cuadro pintado con escrupulosa tersura se deberá buscar en la cercanía de Giovanni Pedrini.

No 72 (Maestro desconocido). María, de perfil, sentada hacia la derecha ofrece el pecho al Niño Jesús. Éste mixa a su Madre y tiene la rodilla derecha levantada. Florentino de la Escuela de Broncino-Pontormo.

La Escuela Boloñesa del siglo xvir está representada por varios cuadros: No 241 (Supuestamente Guido Reni) Busto de Santa Catalina, en marco ovalado. No 250. Busto de Santa Bárbara con un marco igual No 249. Cristo se le aparece a San Luis Gonzaga. No 240: La Coronación de Maria, cuadro redondo con pequeñas figuras que se parece a las pinturas de Giovanni Lanfranco (1580-1647).

De la Escuela Romana existe en la colección el número 241. Figura representada hasta abajo de la rodilla, la Virgen con el Niño dormido, de Sassoferrato (1605-1685).

La Escuela Napolitana está representada por Andrea Vaccaro (1598 hasta 1670). De él es el número 259. San Gregorio, figura de tamaño natural sentada sobre silla roja. El Santo tiene en la mano derecha una pluma para escribir y en la izquierda un libro y escucha con la cabeza levantada la inspiración del Espiritu Santo, el cual le habla como una paloma. Atrás de la silla aparecen cabezas de ángeles. El cuadro está caracterizado igualmente como el siguiente 
por el monograma de Vaccaro. Número 261: San Emilio, Obispo de Ascoli, llevado al cielo por los ángeles. Un angelote sostiene el báculo del Obispo, el otro, un libro sobre el cual están colocados dos pequeños recipientes. Ambos cuadros son dos grandes piezas con mucho efecto que denotan influencia boloñesa.

\section{Holandeses tardios}

No 255 (Rubens) Robo de Proserpina. Nọ 258: Banquete de Tereo. Las dos pinturas tienen pequeñas figuras y son buenos trabajos del taller de Rubens, el cual pintó los mismos temas en dos cuadros que se encuentran ahora en el Museo del Prado en Madrid.

No 252 Gerard Seghers (1591-1651). Adoración de los Reyes Gran composición figurativa de vistoso colorido. El mismo tema se encuentra en un cuadro de G. Seghers, Nuestra Amada Señora, en Brujas.

Nọ 308 (desconocido) Venus se refleja en el escudo de Marte sostenidó por unos cupidos, a la derecha de las tres Gracias, a la izquierda arriba cupidos que flotan en el cielo. Detrás del grupo principal, un cortinaje azul. Jan Lys (nacido alrededor de 1570, muerto en 1629). Comparar del mismo maestro el mismo tema en las Galerías Uffizi № 2179 .

\section{ESCUELA FRANCESA.}

Sin número (Maestro desconocido). Retrato de Marat. En el margen superior del cuadro aparece: Marat l'ami du peuple. Cabeza muy expresiva en perfil de tres cuartos a la derecha, la mirada está dirigida al espectador. El representado tiene puestos un cuello blanco, una faja blanca y una chaqueta rojiza, el fondo es verde oscuro. $\mathrm{El}$ tetrato pintado con un pincel grueso tal vez le hace más justicia al original que el cuadro tan conocido de David, del héroe revolucionario muerto en la tina de baño.

No 285 Jean Auguste Dominique Ingres (1780-1807). San Juan Bautista, firmado: Ingres prinxit Romae. Excelente pintura claramente iluminada de un desnudo de muchacho ante fondo oscuro.

\section{ESCUELA ALEMANA}

Sin número. Friedrich Overbeck (1789-1869) La Anunciación a Maria y Encuentro de Maria e Isabel. Cuadrito ejecutado a manera de miniatura, designado con el monograma F. O. y la fecha 1817.

\section{LA ACADEMIA DE SAN CARLOS EN MÉXICO ${ }^{10}$ \\ II Arte Colonial Mexicano}

La pintura mexicana de la época colonial es una hija de la pintura barroca española, pero al mismo tiempo es también la servidora más fiel y obediente

10 Para la primera parte de este ensayo ver Repertorium, vol. 47 ; p. 144. 
de la Iglesia; porque no sólo son prueba del espiritu religioso del pueblo conquistador las soberbias iglesias barrocas dispersas por todo el país, en regiones solitarias y pobres pueblos indigenas, sino también el arte figurativo y dentro de éste, la pintura más que ningún otro considera su deber más sagrado ser partidaria y propagadora de la fe católica. La elección así como la representación de personas y hechos santos, dan fe de su estrecho parentesco con la pintura de la Madre Patria. Pero evidentemente demuestran también la indiscutible supremacia en el ámbito del arte de la Iglesia y sus prelados, y sobre todo de las órdenes monásticas. Junto a los modelos españoles ejercieron su influencia sobre los pintores mexicanos algunos del arte italiano y en menor medida tal vez del arte flamenco. De los italianos son los venecianos del siglo xvi, la escuela florentina-romana de la misma época y la boloñesa barroca; de los holandeses, Rubens, cuya influencia se percibe más o menos clara en la pintura mexicana. Pero son los hombres de sangre española afín, como Juan de Ruelas, Murillo, Alonso Cano, Velázquez, entre otros, los que se dejan sentir más fuertemente. Por tanto, aunque el arte mexicano es un arte derivado, no se le puede negar su originalidad provinciana y se les reconocerá de buena gana a algunos de sus representantes el haber logrado crear con sus propias fuerzas a la vez utilizando obras de arte extranjeras como inspiración. Fl que a los mexicanos les gustara adomarse con sobrenombres o que se les añadieran algunos, como por ejemplo: Apelles, Miguel Ángel, Ticiano, Correggio, Carracci, tiene su razón de ser en el gusto de la época, pero también demuestra cuán conscientes estaban de su conexión con el arte europeo y su obligación ante éste.

El espiritu católico-religioso de todos los pintores mexicanos se nos manifiesta en forma de una reverente y hasta fanática adoración de la Virgen Maria. Este hecho es para la pintura religiosa una fuente casi inagotable. Un tema favorito de representación religiosa durante los siglos xvir y xviı, tanto en España como en México, fue el de la "Puxísima Concepción". Todos los creyentes encontraban en este cuadro una de las manifestaciones más impresionantes de la fe católica. Los artistas mexicanos competían con sus grandes modelos españoles en la representación de la Virgen suspendida sobre la media luna, todeada de nubes con ángeles y en muchas ocasiones de símbolos de su pureza. Al mismo tiempo existen con frecuencia pinturas de la Mujer Apocalíptica (según el Apocalipsis de San Juan, XII), la Asunción de la Virgen, María, Santa Patrona, "Virgen del Rosario" o "Virgen de los Dolores", Cuadros con temas determinados de la vida de María (Los Esponsales, La Anunciación, La Visitación de Nuestra Señora, La Adoración de los Pastores, La Adoración de los Reyes, Descanso en la Huida) todos eran pintados con gusto, mientras que la representación sencilla de la Virgen y el Niño no parecía ser suficiente para el fervor religioso de los hombres de la Nueva España.

La veneración de Maria juega un papel tan decisivo dentro del campo del arte, que junto a ella las pinturas de Cristo casi pasan a segundo término (como también en España durante la misma época). Es cierto que se encuentran cuadros de la Entrada en Jerusalén, de la Última Cena, de Cristo en Getsemaní, Cristo en la Cruz, del Fntierro, de la Ascensión, y es 
claro que en ninguna iglesia mexicana faltan pinturas del Via Crucis Aun los artistas famosos no desdeñaban pintar Vía Crucis (así Cabrera en la Catedral de Puebla). No obstante, se percibe que la representación de Cristo era menos importante para los artistas que la de la Virgen

El arte mexicano compartía con el arte europeo barroco la predilección por las alegorías religiosas 11 "El Triunfo de la Fe", "El Triunfo de la Iglesia" (grandes murales en las sacristías de las catedrales de México y Puebla) eran obras representativas del gusto contemporáneo. Los Doce Apóstoles, los Cuatro Evangelistas y los Santos Padres, eran también temas populares (los Evangelistas y los Santos Padres se encuentran algunas veces como pinturas en las pechinas de las cúpulas de las iglesias). San Cristóbal era entre los santos el que gozaba de especial popularidad. A él se le pintaba de tamaño gigantesco cerca de las puertas de entrada, porque según una vieja creencia, el día en que uno veía una pintura de San Cristóbal se haća invulnerable a la muerte. Aparte de determinados santos y con más frecuencia de mártires, las vidas y obras de los fundadores de las dos órdenes religiosas importantes para México, franciscanos y dominicanos, eran las que ofrecian temas agradables a los pintores. También encontró acogida en el arte mexicano: San Antonio, al cual se le revela Cristo en una aparición (pintado repetidas veces por Murillo); más tarde hicieron su entrada hombres y mujeres canonizados como: San Juan de Dios, San Ignacio de Loyola, San Felipe Neri, San Francisco de Sales, Santa Teresa de Jesús.

Los ejemplos de pintura religiosa barroca se encuentran probablemente en todas las iglesias del país, aunque muchas veces en pésimo estado, colgadas en oscuras capillas o apenas visibles en retablos gigantescos, enmarcadas por una opulenta decoración dorada que, como en España, cubre hasta el techo las paredes de las iglesias. Las pinturas en las paredes de la Academia son asequibles al estudio y hacia ellas queremos dirigir nuestra atención, toda vez que constituyen un buen aspecto general de la producción total de los pintores mexicanos más importantes del barroco y rococó

Baltazar de Echave (también Chávez) el Viejo; nativo de Fspaña, se le considera como fundador de la escuela mexicana de pintura. Su obra más importante se localiza dentro de la primera mitad del siglo xvi 12 La Academia contiene de él: Martirio de San Aproniano, fechado 1612 Gran cuadro figurativo con figuras llenas de un animado movimiento, algunas de ellas con indumentaria arcaizante. Los bustos y las cabezas en la parte anterior corresponden

11 Los modelos de Rubens para gobelinos que representaban el "Triunfo de la $\mathrm{Fe}$ ", tuvieron una influencia que se dejó sentir en México.

12 Echave se casa el 7 de diciembre de 1623 con Ana de Arriola. Fl 25 de abril de 1630, bautizo de su hija Josefa, el 30 de octubre de 1632 el de su hijo Baltazar ("el mozo"), el 7 de julio de 1636 el de su hijo Juan. Documentos proporcionados por el licenciado F. Pérez Salazar, Algunos Datos Sobre la Pintura en la Época Colonial. México, 1923, $\mathrm{p}_{\mathrm{n}} 276 \mathrm{ff}$. Ver dato en Mémoires de la societé Alzate, tomo 41. Una breve clasifcación de pintores mexicanos contenida en Breves apuntes sobre la Antigua Escuela de Pintura en México, por Agustín F. Villa con Prólogo y notas de Alfonso Toro. México, 1919. También: F. D. Barroso, El Arte en Nueva España, México, 1921. 
a aquellas populares figirantes (sic) de la pintura del renacimiento italiano tardío, que ofrecían al pintor una bienvenida oportunidad de probar su habilidad para el dibujo. Aquí, como en El Martirio de San Lorenzo, al pintor le importaban principalmente el dibujo, el movimiento y la reproducción del cuerpo humano desnudo. Se percibe aún el leve recuerdo del ejemplo de Miguel Ángel y, más bien, de sus sucesores. En el Martirio de San Ponciano, la construcción, la relación de todas las figuras secundarias con la principal, la representación del cuerpo desnudo o a medio vestir, constituyen en realidad el problema principal, mientras que a lo pictórico en su verdadero sentido se le atribuye menos importancia.

Por el contrario hay otros cuadros del maestro donde el desarrollo pictórico perfecto tiene un énfasis especial. Por ejemplo: una Adoración de los Reyes designada con el nombre del artista ("Echave fecit"). Al contemplar los brillantes colores, las costosas vasijas y coronas pintadas con sumo cuidado, las ricas vestimentas reales, el ropaje rojo y azul de María, surge el recuerdo de los insignes venecianos del siglo xvi. De igual manera el Encuentro de Maria e Isabel (la Academia posee dos interpretaciones diferentes del mismo tema) está especialmente orientado hacia realzar el efecto pictórico. En un cuadro aparecen: Isabel con un manto perduzco, María con sus colores tradicionales (manto azul, vestido rojo). Un cielo nublado y oscuro se abre para dejar pasar brillantes rayos de luz, que dan una iluminación muy significativa al grupo de las dos mujeres. Los colores vivos e intensos están unidos en una armonía melodiosa. En el otro cuadro de la Visitación las dos mujeres caminan una junto a la otra tomadas de la mano. Sobre sus cabezas está suspendida la paloma del Espíritu Santo. María viste un vestido rojo brillante, sobre éste lleva un manto azul oscuro; Isabel, un vestido gris y manto amarillo oro y pañoleta blanca. Atrás de ellas vemos a José y a Zacarías "El contraste entre el fondo oscuro y las figuras grandes del frente cuyos ropajes llenos de colorido proporcionan un brillo resplandeciente a todo el cuadro, está puesto de relieve con mucho efecto. Cristo en Getsemaní, es el tema de otro cuadro que destaca igualmente el talento pictórico del artista, Cristo, vestido con vestimenta roja y manto azul, está arrodillado ante un ángel que aparece en una nube y le ofrece el cáliz.. Por la derecha, en el fondo, surgen de la oscuridad esbirros con antorchas, mientras que la media luna ilumina la escena nocturna con un débil rayo de luz La aparición luminosa en un lado del cuadro y las antorchas y la luna en el otro, esparcen una iluminación muy particular. Otra prueba de su talento pictórico las constituyen el cuadro de La Porciúncula y el de la Anunciación a Maria. San Francisco, con hábito de color gris-café está arrodillado frente a Cristo y María entronizados en nubes, ambos ataviados con mantos azul oscuro y vestidos rojos; el verde intenso de la cortina constituye el complemento pictórico a ellos. Aquí todo está visto con grandeza, simplificado. A través de la distribución de lo claro y lo oscuro se logra un nítido contraste $y$, sin embargo, todo queda unido pictóricamente. En la Anunciación el encanto del cuadro radica en el efecto contrastante de los colores fuertes y oscuros de las vestimentas con los tonos pálidos de la piel, así como en el contraste entre la nube oscura y la brillante paloma del Espiritu Santo. El inquieto San Miguel, 
que produce un fuerte efecto de amaneramiento, es de los trabajos menos logrados del artista. La Apoteosis de la Virgen atribuida a él tiene únicamente un interés objetivo.

Sebastián de Arteaga fue contemporáneo de Echave y como éste fue influenciado por el arte italiano. Además de pintor exa escribano de la Inquisición. Tomás el Incrédulo, cuadro de grandes figuras existentes en la Academia, presenta a De Arteaga desde su mejor ángulo, como un artista de aspiraciones elevadas que logró admirablemente la modelación cuidadosa del cuerpo claramente iluminado de Cristo, así como la caracterización de las cabezas barbadas. de los Apóstoles. Otra obra, los Esponsales de Maria, está diseñada absolutamente acorde al espíritu del alto Renacimiento italiano ${ }^{13}$

Es una composición estrictamente equilibrada donde el sacerdote aparece al centro, visto totalmente de frente, los desposados con una actitud modesta y humilde a su izquierda y derecha, las esquinas las ocupan las figuras de acompañamiento y hay también una corona de ángeles en una nube luminosa.

A Luis Juárez, otro contemporáneo de Echave el Viejo, lo podríamos llamar, si es que deseamos comparar a nuestras grandezas mexicanas coloniales con los italianos, el Baroccio de México. De él son características una cierta elegancia en todas las figuras, la pincelada ancha, el suave efecto de los colores, la expresión, casi rayando en lo dulce, de sus ángeles espléndidamente colocados. Lo mejor de él aparece en el cuadro de Getsemani, al cual no se le puede negar una emoción más profunda. En los Esponsales de Santa Catalina llaman la atención los ángeles con sus cabezas redondas, frentes altas rodeadas de rizos, naricillas respingadas y bocas sonrientes. Una Anunciación con figuras de tamaño medio natural presenta un buen efecto cromático. Toda la luz está concentrada sobre el rostro y las manos de María, el ángel, la paloma del Fspiritu Santo y Dios Padre, mientras que el resto del cuadro forma un contraste de color con ellos.

El cuadro de San Ildefonso, que recibe la casulla de manos de María, no deja de tener valor pictórico (Juárez repitió el mismo tema pero con figuras. pequeñas). En el frente del cuadro que ocupa la figura del Santo predominan los tonos rojos cálidos; en la parte superior del mismo, donde se hace visible la aparición celestial, son los tonos más fríos de azul y gris los que tienen preponderancia.

Baltazar de Echave el Joven (el Mozo). Nacido el 30 de octubre de 1632 y fallecido el 14 de enero de 1682. Hijo de Baltazar el Viejo, es un artista barroco con un enfoque más manifiestamente español que italiano. Son distintivas de sus pinturas las apariciones luminosas brillantes, la expresión espiritual intensificada, el movimiento a cualquier precio, el hacer destacar todos los momentos esenciales del cuadro, pero un desarrollo descuidado en los detalles. Un Entierro de Cristo (firmado Baltasar de Echave Anno 1665) caracteriza de la mejor manera los esfuerzos del axtista por lograr efectos intensos. Toda la luz se concentra sobre el cadáver de Cristo que reposa sobre un lienzo

13 Si aquel cuadro recuerda a Ribera y Zurbarán, éste recuerrla en la compositión del grupo principal a Perugino. 
blanco y está colocado en forma diagonal en el cuadro. Lo ilumina un discípulo situado en el lado izquierdo de la pintura quien sostiene en alto una antorcha, cuya luz parpadeante pasa rápidamente sobre algunas cabezas y deja en profunda sombra otras partes de las figuras. En su Martirio de San Pedro Arbues el afán del pintor está dirigido a expresar una emoción intensificada y una pasión significativa. Está pintado con un gusto evidente por los contrastes brillantes de luz y sombra y los ademanes conmovedores, pero también por lo horripilante.

De José Juárez, supuestamente un discípulo de Echave el Viejo, se conoce poco. Es posible que una constancia de bautizo de un hijo José, del 2 de junio de 1631 , se refiera a nuestro pintor ${ }^{14} \mathrm{Su}$ hija Antonia se casa el 8 de septiembre de 1650 con Antonio Rodríguez. 15 José fue abuelo de José Rodríguez Juárez. Del pintor más viejo del mismo nombre, se encuentra en posesión de la Academia un gran cuadro de iglesia rico en figuras, que se refiere al martirio de los hermanos españoles Justo y Pastor que murieron de muchachos por ser cristianos. El tema era perfecto para un fanático pintor religioso, pero en su ejecución el resultado final es frío y poco satisfactorio. Lo repulsivo del asunto no está suavizado de ninguna manera por los méritos pictóricos del cuadro La Aparición de la Virgen ante San Francisco de Asis, es muy española en el sentimiento. La profusión de ángeles demuestra hasta la saciedad de cuánta veneración eran objeto en este país. En esta pintura luces deslumbradoras se encuentran directamente junto a sombras oscuras. Así lo exigía el gusto de la época que encontraba una satisfacción estética en estos abruptos contrastes. Una gran Adoración de los Reyes, se significa por la ejecución amable así como por el gusto por los accesorios ornamentales. El pintor puso todo su cuidado en la representación de los suntuosos ropajes reales y los recipientes resplandecientes de oro y piedras preciosas que fueron dadas en ofrenda al Divino Niño. Telas, joyas, utensilios de oro y plata están tan minuciosamente reproducidos que podrían servir de modelo para artesanias. El grupo del rey moro y dos acompañantes que forman un conjunto oscuro, se destacan con nitidez del fondo claro, mientras que, por el contrario, la Madre y el Niño proyectan su luminosidad desde sus alrededores oscuros. ${ }^{16}$ Juan Correa 17 representa la transición a el arte del siglo xvir. En la Academia existe una Santa Catalina de él La Santa, interpretada y ataviada

14 F. Pérez Salazar, op cit.

$15 \mathrm{~F}$. Pérez Salazar, op. cit.

$16 \mathrm{El}$ nombre (del pintor) aparece dentro de una tapa que está en el suelo en la parte de adelante cerca del margen. La fecha de 1699 es difícilmente compaginable con el carácter del cuadro y las fechas de la vida de José Juárez, arriba mencionadas.

17 Podemos deducir: de cuanta consideración y prestigio gozaba Correa, por el hecho de que fue considerado digno de copiar la imagen milagrosa de Guadalupe, que fue distribuida después en cientos de reproducciones por todas las iglesias del país. Varios pintores del siglo xviI, como Cabrera, Ibarra, Sánchez y José Rudecindo fueron sus alumnos. En la catedral de México existen varias obras grandes de él (Representación del Apocalipsis, Alegoría de la Iglesia, Asunción de María, entre otros). 
como una dama distinguida, se apoya con la mano izquierda, indolentemente y con un dejo de elegancia, sobre una larga y puntiaguda espada, con la derecha sostiene una hoja de palma. Del cielo nublado se asoman cabezas de ángeles que observan a la noble figura femenina de apariencia totalmente mundana. A sus pies se encuentra una rueda, que es su instrumento de martirio. Figuras particulares de santos y santas fueron un tema popular tanto para la pintura barroca española como para la mexicana. Sin embargo, la Santa de nuestro cuadro no transmite nada de aquella tormenta espiritual que era representativa de las obras más antiguas, sino que más bien, siguiendo el gusto diferente de la época, tiene una actitud más cortesana y formal

Contemporáneo de Correa y nieto del ya mencionado José Juárez, Juan (José) Rodríguez Juárez, nació el 14 de julio de 1675 y murió el 14 de enero de 1728, 18 Se le comparó con Carracci y hasta se le llegó a nombrar el Apeles mexicano, apelativos que ciertamente no se entienden en cuanto a su pintura se refiere. San Jaan de Dios, monje de tamaño natural, de pie, rodeado de paisaje, recuerda por la expresión beatífica de su rostro a los cuadros españoles del siglo xvir, por lo demás no se le puede comparar con la representación que del mismo santo hizo Zurbarán y que se encuentra también en la Academia. El cuadro que le hace juego es uno de Santa Ana quien con un porte distinguido y expresión amable lleva de la mano a la pequeña María La madre está vestida con un atuendo de color verde olivo sobre el cual lleva un manto rojo oxidado, mientras que la niña está envuelta en un manto azul oscuro con finos bordados en oro. Esta pintura está caracterizada favorablemente por una actitud tranquila sin afectación y la construcción simple y grande. Su Autorretrato pintado con facilidad, aunque un tanto descuidadamente, también se encuentra en la Academia 19

José María Ibarra, nacido en 1688 en Guadalajara, fallecido en 1756, fue un discípulo de Juan Correa. Se dice que él mismo se nombraba el Murillo mexicano, nosotros preferiríamos llamarlo el Carlo Maratta mexicano. Cuatro cuadros que forman una serie con figuras de tamaño natural, muestran un estilo pictórico pulido aunque algo dulzón, verdaderamente churrigueresco. Los cuadros se intitulan: Cristo en la casa de Simón, La Sangrante (sic), La Samaritana en la fuente, Cristo en la casa de la Adúltera. En estas pinturas se encuentra todo lo que preocupaba a los pintores de generaciones anteriores como: los juegos de luz y sombra de gran efecto, movimientos llenos de pasión, una fuerte agitación espiritual, colores brillantes, el agrupamiento complicado de las figuras, sólo que aquí se encuentra debilitado, hasta podríamos decir que diluído. 20

Otro de los discipulos de Correa, Miguel Cabrera, lleva el dudoso nombre

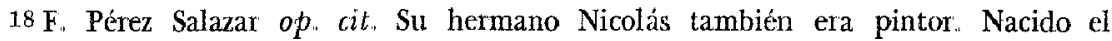
5 de enero de 1667 , casado el 8 de septiembre de 1688, sepultado en julio de 1734. Un "Triunfo de la Virgen" de Nicolás está fechado 1699 .

19 El importante "Altar de los Reyes" en la Catedral de México con una Adoración de los Reyes como obra central, es el trabajo más importante de nuestro artista.

20 Otros cuadros de él en la Catedral de Puebla, con representaciones de la vida de María. 
honorario de ese pintor instantáneo que fue Giordano. Todavía más improcedente es por supuesto el epíteto que irreflexivamente se le quiso adjudicar del Miguel Ángel mexicano. Nacido de padres españoles el 27 de febrero de 1695 en Oaxaca y fallecido en la ciudad de México el 16 de mayo de 1768, Cabrera influenció de manera permanente la pintura mexicana del siglo xurir. El colorido de Cabrera se distingue por sus tonos claros, un poco desvanecidos y armoniosos que eran propios de esa época galante tanto en la vieja Europa como en la Nueva España. Sus dos figuras de santos de tamaño natural, San Bernardo, el Abad y San Anselmo, pintadas según el gusto de la época sin gran movimiento corporal y sin gran profundidad espiritual, nos ofrecen en la armonía de sus tonos blancos, grises, azul claros y rojos frambuesa, un buen ejemplo del ideal colorístico del siglo xvin con su famosa "Morbidezza", La muy admirada Virgen del Apocalipsis, que se encuentra en la Academia (ca. 1760), es una composición exuberante donde la figura central es María con el Niño en brazos. ${ }^{21}$ La Virgen suspendida sobre el globo terrestre le pisa la cabeza a una serpiente. A la izquierda el arcángel Miguel lucha con el dragón, a la derecha aparecen unos ángeles con diferentes símbolos (la azucena, la rosa y el espejo). Dios Padre en las nubes y San Juan en Patmos, completan el cuadro, cuyo amplio simbolismo no es fácilmente accesible a nosotros, pero que corresponde totalmente a la época. Conservar la unidad pictórica y gráfica de las figuras y los símbolos mezclados en las esferas celestial y terrestre, fue una tarea fácil para el artista, como lo comprueba además del cuadro ya mencionado, el de San José como Santo Patrono. Cabreta fue nombrado director de la Academia de Pintura en México en 1753, y llegó a ser académico de la más pura cepa en el sentido del rococó 22 En su taller empleaba a un gran número de aprendices, sin cuya ayuda no hubiera sido posible una actividad tan vasta como la suya, ya que su nombre se encuentra por todos lados.

La pintura mexicana, en tanto que fue educada y maduró en el espíritu del barroco y en el espíritu de un pensamiento religioso eclesiástico unilateral, tuvo un digno fin con Cabrera y su círculo.

21 Según el cuadro de Rubens en la Pinacoteca de Munich.

22 En 1766 redactó Cabrera un artículo donde comprobaba la procedencia sobrenatural de la imagen milagrosa de la Virgen de Guadalupe en México. 